\title{
Relationship between germination and bell pepper seed structure assessed by the X-ray test
}

\author{
Bruna Gagliardi ${ }^{1}$, Julio Marcos-Filho2* \\ ${ }^{1}$ USP/ESALQ - Programa de Pós-Graduação em Fitotecnia. \\ ${ }^{2}$ USP/ESALQ - Depto. de Produção Vegetal, C.P. 09 - 13418-900 - Piracicaba, SP - Brasil. \\ *Corresponding author <jmarcos@esalq.usp.br> \\ Edited by: Edmilson José Ambrosano
}

\begin{abstract}
Alternative use of the X-ray test to evaluate seed quality has become increasingly diverse. This study was performed primarily to establish experimental procedures and verify the effectiveness of the X-ray test to detect damage or abnormalities in bell pepper (Capsicum annuum) seed structure associated with germination. Five seed lots each of hybrids Reinger and Sentinel were used. Two hundred seeds per lot were exposed to durations and intensities of X-radiation and visually classified into four categories according to the proportion between the area occupied by the embryo and endosperm in relation to the total cavity area in the internal seed structure, e.g. $0,<50 \%, 50-75 \%$ and $100 \%$. The last category was subdivided into two others based on the occurrence of morphological abnormalities. Seed samples obtained from different X-ray categories were then submitted to germination test at $25^{\circ} \mathrm{C}$ for 14 days and subsequently compared with results of the X-ray analysis. Exposure to a $10 \mathrm{kV}$ radiation for $260 \mathrm{~s}$ was the most suitable X-ray dose for visualizing seed structure. Seeds in which the area of the internal cavity occupied by the embryo and endosperm varied from $50-75 \%$ produced abnormal seedlings or did not germinate. Full seeds (100\% of the internal cavity area occupied) with abnormal structure usually originated defective seedlings. As a consequence, the classification of bell pepper seeds according to the proportion occupied by the seed content (embryo + endosperm) allowed a reliable estimation of the degree of seed physical integrity based on X-ray analysis and its association with germination performance.

Key words: seed analysis, embryo morphology, physical integrity
\end{abstract}

\section{Introduction}

The objective of including the X-ray test in Rules for Seed Testing (Brasil, 1992) was to complement information provided by the germination test. Before the germination test seeds may be previously exposed to X-rays and classified as well formed, empty or damaged. The exposition period, together with a fixed miliamperage of the X-ray unit, regulates the dose of X-rays that determine the radiograph density and the degree of contrast and image quality. In this way, different voltage/exposition periods have been adopted in seed radiography according to the plant species, X-ray equipment, and sensitivity of the available radiographic film (Simak, 1980).

Although X-rays are potentially harmful, seeds are exposed to relatively low doses during the test so as to not provoke or to adversely affect germination (Simak and Gustafsson, 1953; Bino et al., 1993). Furthermore, X-ray analysis is a non-destructive, quick method that is relatively simple to perform.

Morphological aspects of seeds possibly associated with viability may be evaluated by the X-ray test. For this reason, several researchers have reported relations between seed structure and germination or seedling morphology, obtaining information that varies according to the species (Simak, 1991). Among these are tomato - Solanum lycopersicum L. (Van Der Burg et al., 1994), corn - Zea mays L. (Cícero et al., 1998; Carvalho et al., 1999), bell pepper - Capsicum anuum (Dell'Aquila, 2007a), embaúba - Cecropia pachystachya Trec. (Pupim et al., 2008), Eugenia pleurantha (Masetto et al., 2007), and papaya - Carica papaya L. (Santos et al., 2009).
In addition, Goodman et al. (2005) scored radiographic images of the northern red oak's (Quercus rubra L.) acorns according to the degree of cotyledon-cotyledon and cotyledonpericarp separation and demonstrated the potential of X-ray image analysis to provide a rapid and nondestructive estimation of acorn viability and its relation with seed desiccation tolerance.

A lack of information on the association of X-ray analysis and seed viability in vegetable seeds to evaluate seed viability emphasizes the need for research in this area. The objective of this study was to evaluate the potential of the $\mathrm{X}$ ray test in identifying damage and abnormalities in bell pepper seeds by estimation of the proportion between the area occupied by the (embryo + endosperm) and the total cavity area in the internal structure of the seed as well as possible relationships with germination.

\section{Materials and Methods}

Five lots each of two bell pepper hybrids Red Reinger (germination from $81 \%$ to $83 \%$ ) and Green Sentinel (germination from $83 \%$ to $93 \%$ ) were used. Before X-ray analysis, seed water content (average of 6\%) was adjusted to $10 \%$, $12 \%, 15 \%, 18 \%$ and $20 \%$ in order to obtain clear and precise radiograph images. For this, the humid atmosphere method was used (Rossetto et al., 1995) in samples of approximately five grams distributed in a single layer on a screen suspended in a plastic box $(115 \times 115 \times 35 \mathrm{~mm})$ as used for accelerated aging tests. Boxes were closed and kept in a chamber at $20^{\circ} \mathrm{C}$. Seed water content was monitored by successive weighing until the desired level was obtained. Seeds 
from each moistened sample were then stored in closed containers for seven days to standardize the distribution of water within each seed sample. After reaching the desired moisture content, four replications of 50 seeds each were submitted to X-ray analysis. Seeds were placed in individual cells of an acrylic plate and positioned so that the embryo axis remained parallel to the plate surface.

A Hewlett-Packard (model MX-20) Faxitron X-ray device was used to obtain the radiographic images. Each acrylic plate with seeds was placed directly on a radiographic film (Kodak MIN-R 2000, size $18 \times 24 \mathrm{~cm}$ ) at $58 \mathrm{~cm}$ from the radiation source. Combinations of radiation intensity/exposition period were tested: $10 \mathrm{kV} / 260 \mathrm{~s}, 10 \mathrm{kV} / 270 \mathrm{~s}, 10 \mathrm{kV} /$ $280 \mathrm{~s}, 13 \mathrm{kV} / 50 \mathrm{~s}, 13 \mathrm{kV} / 75 \mathrm{~s}, 13 \mathrm{kV} / 90 \mathrm{~s}, 15 \mathrm{kV} / 75 \mathrm{~s}, 25 \mathrm{kV} / 75 \mathrm{~s}$, $25 \mathrm{kV} / 30 \mathrm{~s}$ and $35 \mathrm{kV} / 10 \mathrm{~s}$. The film was processed in a Hope MicroMAX automatic X-ray film processer (model 319) and visualized on a Hoefer transilluminator (model VIS-4). Seed radiograph images were then digitized using an Umax scanner (Power Look model 1100) for enlargement and viewing by a computer unit (Pentium III, $600 \mathrm{MHZ}, 256 \mathrm{MB}$ memory, 20 GB HD Ultra SCSI and 21-inch monitor).

To assure the potential of the image analysis in identifying possible embryo damage and/or defects, seeds from each lot were previously numbered, exposed to X-rays and submitted to a germination test in four replicates of 25 seed distributed on blotting paper in plastic boxes $(115 \times 115$ $\times 35 \mathrm{~mm}$ ). The substrate was moistened with water at 2.5 times its weight. The test was interpreted 14 days after sowing (Brasil/MAPA, 2009). Normal seedlings, abnormal seedlings and non-germinated seeds were photographed individually using a Nikon digital camera (model D1) connected to the used computer unit. In this way, all images (X-ray and photo) could be simultaneously examined, allowing the internal seed structure (X-ray) to be compared with corresponding seedling obtained upon the completion of the germination test.

Radiographic analysis of seeds was based on the stages of embryo development established according to the portion of the seed cavity occupied by the embryo and endosperm, visually estimated as 0 (empty seed), $<50 \%, 50$ $75 \%$ and $100 \%$. Seeds with a $100 \%$ ratio were classified according to embryo morphology as normal or abnormal. Normal seeds were those with intact embryos (complete with developed parts) and those with limited damage (more than $50 \%$ functional cotyledons). Seeds with damage to the embryo axis were excluded (Machado and Cícero, 2003).
X-ray data were not analyzed statistically. The quantity of seeds in each category was reported as a percentage of the total number of seeds evaluated in each lot and associated to a percentage of normal seedlings, abnormal seedlings and non germinated seeds computed in the germination test.

\section{Results and Discussion}

Initial X-ray tests did not produce consistent results due to the difficulty in correctly identifying seed parts in most of the radiograph images. It is possible that exposing relatively dry seeds (6.0\% moisture content) to X-rays caused this difficulty. To determine the ideal seed water content for improving the radiograph image without promoting increases in seed deterioration, seed water content was adjusted to $10 \%$, $12 \%, 15 \%, 18 \%$ and $20 \%$ of their water content. The least amount of water necessary was determined to be $12 \%$. Radiographs of seeds with this level of water content provided sufficiently visible images of seed structure for reliable interpretation (Figure 1). This procedure is probably necessary to obtain clear X-ray images of relatively small seeds, such as bell pepper, without a drastic alteration of seed water content and performance. This means that it was not confirmed here that drier seeds usually exhibit clearer X-Ray images; probably, it is necessary to define more precisely whether the seed water content affects the quality of the radiography of seed species.

Seed exposition to $10 \mathrm{kV}$ radiation for $260 \mathrm{~s}$ enabled clear visualization of bell pepper seed internal structure. The other used intensities $(13 \mathrm{kV}, 15 \mathrm{kV}, 25 \mathrm{kV}$ and $35 \mathrm{kV})$ resulted in darker images, regardless of the exposition time, which did not permit adequate visualization of the seed parts. Regulation of the X-ray machine depends on seed dimension, density and composition as well as type of equipment used (ISTA, 1996).

The combination of light and dark tones observed in radiograph images is determined by the quantity of X-rays absorbed by distinct seed regions (Simak, 1980; ISTA, 1996). When the internal cavity is not completely filled by embryo and endosperm tissue or contains less dense tissue, X-ray analysis produced images with dark spots, since resistance was not sufficient to block X-ray passage (Figure 2A). Seeds that were fully filled by the embryo and endosperm possess a low optical density and provided much clearer images, since there was higher resistance to the radiation passage (Sahlen et al., 1995), as shown in Figure 2B. In this way, it was evident
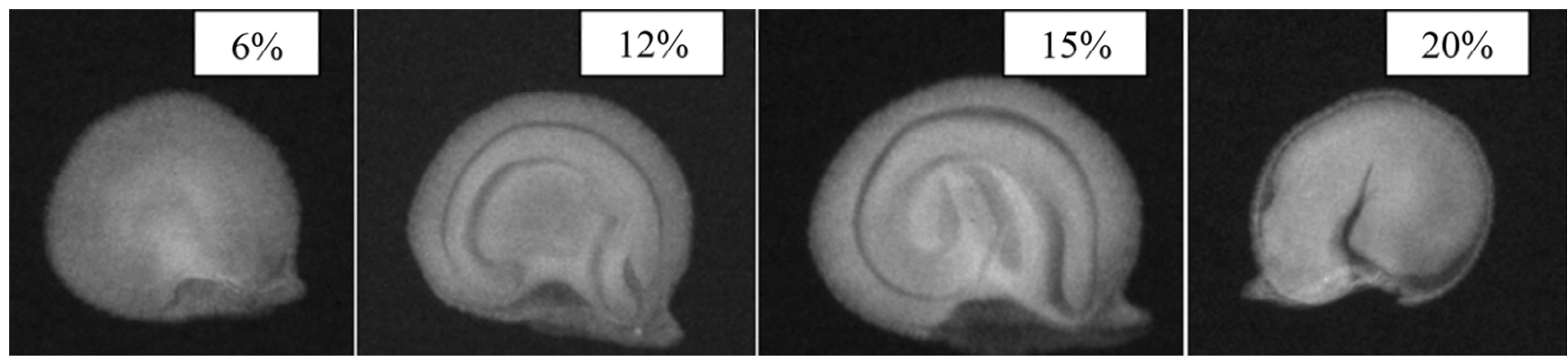

Figure 1 - Radiographic images of seeds with water contents of $6 \%, 12 \%, 15 \%$ and $20 \%$. 
that the X-ray test could detect differences in bell pepper seed structure (Figure 2-A and B).

Classification of seeds with less than $100 \%$ of the internal cavity occupied by the embryo and endosperm was based on estimates of areas with free spaces between the tegument and endosperm (Figure 3A) and between the endosperm and embryo (Figure 3B).

The use of X-ray analysis to associate seed morphology and viability was first documented in 1991 by Simak. In this study, morphological abnormalities in bell pepper seeds were classified as either damaged (Figure 4A and B) or malformed embryos (Figure 4C). Fewer dense tissues in these figures correspond to darker areas, probably associated with damage or developmental abnormalities.

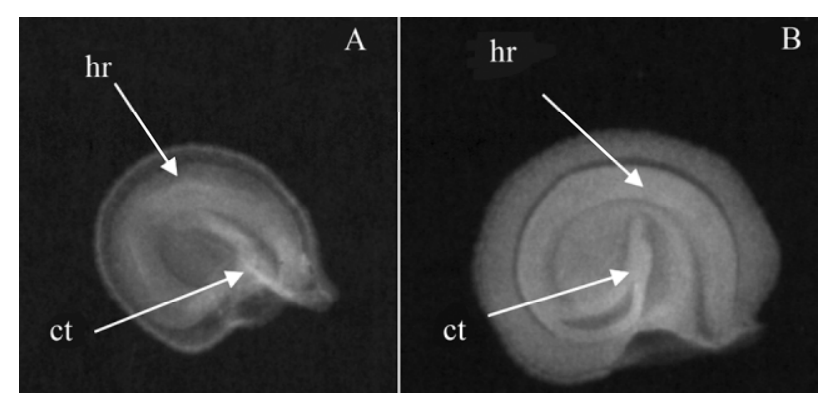

Figure 2 - Radiographic images of bell pepper seeds with embryonic cavity partially filled (A) and totally filled (B). $\mathrm{Ct}$ - cotyledons, hr - hypocotyl-radicle axis.
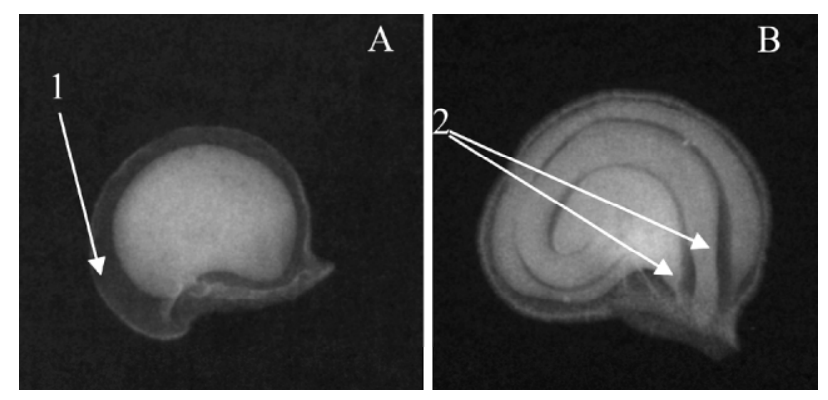

Figure 3 - Radiographic images of retraction of the endosperm (A), and space between endosperm and embryo (B). 1 - retraction of the endosperm (dark area between tegument and endosperm). 2 - space between embryo axis and endosperm (dark area).

No empty seeds or seeds with less than $50 \%$ of the internal cavity occupied by the embryo and endosperm were detected in the five 'Reinger' seed lots (Table 1). Percentage of seeds with $50-75 \%$ filled internal cavity was relatively low, varying between $5 \%$ and $6 \%$. 'Sentinel' seed lots (Table 1) also did not show any empty seeds or seeds with less than $50 \%$ filled cavity, whereas seeds with $50-70 \%$ filled internal cavity varied between $3-12 \%$. This relatively low proportion of malformed seeds was not totally surprising, since the hybrid seeds utilized in the present study have been carefully produced and processed resulting in high physiological potential.

In general, the quantity of 'Reinger' seeds with completely developed embryo and endosperm (100\% filled cavity) and classified as normal by the X-ray test (Table 1 ) was comparable to the percentage of normal seedlings recorded in the germination test (Table 2). A relatively small quantity of these well formed seeds resulted in abnormal seedlings or non germinated seeds, which may be due to adverse factors such as microorganisms or natural seed deterioration with any visible symptoms on the radiograph images (Van Der Burg et al., 1994). Classification of Sentinel seeds based on

Table 1 - Number of 'Reinger' and 'Sentinel' bell pepper seeds classified according to the proportion of the internal seed cavity occupied by the embryo and endosperm based on X-ray test results.

\begin{tabular}{|c|c|c|c|c|c|c|}
\hline \multirow{3}{*}{ Hybrid } & \multirow{3}{*}{ Lot } & \multicolumn{5}{|c|}{ Seed cavity occupation } \\
\hline & & \multirow{2}{*}{0} & \multirow{2}{*}{$<50$} & \multirow{2}{*}{$50-75$} & \multicolumn{2}{|c|}{100} \\
\hline & & & & & $\mathrm{N}$ & A \\
\hline & & 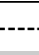 & ------- & $-\%--$ & ---- & $-\cdots$ \\
\hline \multirow{5}{*}{ Reinger } & 1 & 0 & 0 & 5 & 95 & 0 \\
\hline & 2 & 0 & 0 & 5 & 91 & 4 \\
\hline & 3 & 0 & 0 & 6 & 88 & 6 \\
\hline & 4 & 0 & 0 & 5 & 93 & 2 \\
\hline & 5 & 0 & 0 & 5 & 91 & 4 \\
\hline \multirow{5}{*}{ Sentinel } & 6 & 0 & 0 & 11 & 85 & 4 \\
\hline & 7 & 0 & 0 & 5 & 93 & 2 \\
\hline & 8 & 0 & 0 & 3 & 95 & 2 \\
\hline & 9 & 0 & 0 & 12 & 81 & 7 \\
\hline & 10 & 0 & 0 & 3 & 95 & 2 \\
\hline
\end{tabular}
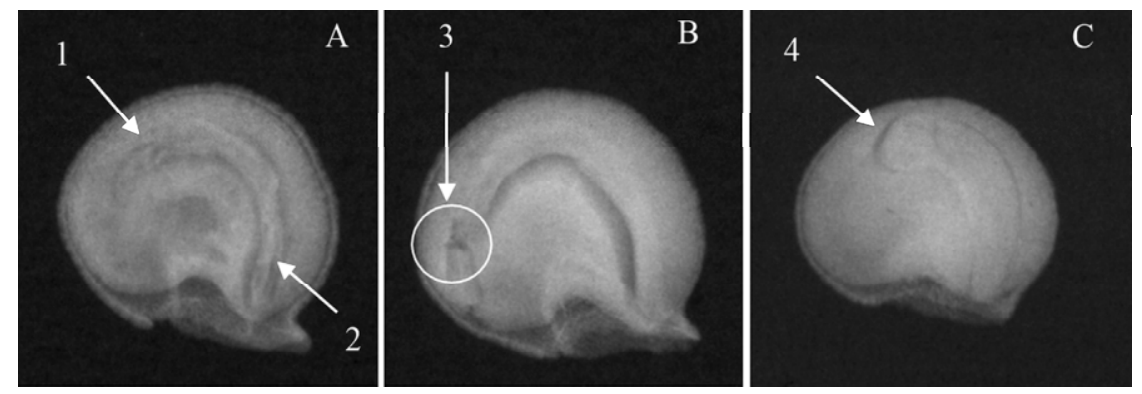

Figure 4 - Radiographic images of damaged (A and B) and malformed (C) embryos of bell pepper seeds. 1 - less dense cotyledon tissue (dark region of embryo axis); 2 - less dense radicle tissue (dark region of embryo axis). 3 - broken cotyledons; 4 - no differentiation of cotyledon leaves. 
X-ray test results (Table 1 ) was directly related with germination in lots 7, 8 and 10 (Table 2). On the other hand, in lots 6 and 9 of this hybrid, a large portion (12-15\%) of full (100\%) normal seeds originated abnormal seedlings or dead seeds.

The research on X-ray analysis to identify normal seeds among completely full bell pepper seeds should be improved through further research avoiding the source of errors and subjectivity of the visual inspection to seed structure scoring. One available option is the use of a Tomato Analyzer software developed for the semi-automatic evaluation of the

Table 2 - Percentage of Normal Seedlings (NS), Abnormal Seedlings (AS) and Non-Germinated Seeds (NGS), of 'Reinger' and 'Sentinel' bell pepper lots classified associated to the percentage of seed cavity occupation (X-ray test results).

\begin{tabular}{|c|c|c|c|c|c|c|}
\hline \multirow{3}{*}{ Hybrid } & \multirow{3}{*}{ Lot } & \multicolumn{4}{|c|}{ Seed cavity occupation } & \multirow{3}{*}{ Total } \\
\hline & & \multirow{2}{*}{ Category } & \multirow{2}{*}{$50-75$} & \multicolumn{2}{|c|}{100} & \\
\hline & & & & NS & AS & \\
\hline \multirow{16}{*}{ Reinger } & \multirow{4}{*}{1} & \multicolumn{5}{|c|}{--------- \% ---------- } \\
\hline & & NS & 02 & 89 & 00 & 91 \\
\hline & & AS & 02 & 06 & 00 & 08 \\
\hline & & NGS & 01 & 00 & 00 & 01 \\
\hline & \multirow{3}{*}{2} & NS & 01 & 84 & 00 & 85 \\
\hline & & AS & 04 & 05 & 03 & 13 \\
\hline & & NGS & 00 & 01 & 01 & 02 \\
\hline & \multirow{3}{*}{3} & NS & 01 & 82 & 00 & 83 \\
\hline & & AS & 03 & 06 & 03 & 12 \\
\hline & & NGS & 02 & 00 & 03 & 05 \\
\hline & \multirow{3}{*}{4} & NS & 02 & 84 & 00 & 86 \\
\hline & & AS & 02 & 08 & 02 & 12 \\
\hline & & NGS & 01 & 01 & 00 & 02 \\
\hline & \multirow{3}{*}{5} & NS & 00 & 85 & 00 & 85 \\
\hline & & AS & 04 & 06 & 03 & 13 \\
\hline & & NGS & 01 & 00 & 01 & 02 \\
\hline \multirow{15}{*}{ Sentinel } & \multirow{3}{*}{6} & NS & 07 & 66 & 00 & 73 \\
\hline & & AS & 03 & 14 & 05 & 22 \\
\hline & & NGS & 02 & 01 & 02 & 05 \\
\hline & \multirow{3}{*}{7} & $\mathrm{NS}$ & 01 & 89 & 00 & 90 \\
\hline & & AS & 02 & 03 & 01 & 06 \\
\hline & & NGS & 02 & 01 & 01 & 04 \\
\hline & \multirow{3}{*}{8} & NS & 02 & 90 & 00 & 92 \\
\hline & & AS & 00 & 05 & 02 & 07 \\
\hline & & NGS & 01 & 00 & 00 & 01 \\
\hline & \multirow{3}{*}{9} & NS & 05 & 60 & 00 & 65 \\
\hline & & AS & 03 & 14 & 03 & 20 \\
\hline & & NGS & 04 & 10 & 01 & 15 \\
\hline & \multirow{3}{*}{10} & $\mathrm{NS}$ & 01 & 88 & 00 & 89 \\
\hline & & AS & 01 & 07 & 02 & 10 \\
\hline & & NGS & 01 & 00 & 00 & 01 \\
\hline
\end{tabular}

phenotypic characteristics of fruits, which can be adapted to seed analysis. This software can substitute the determination of some morphological attributes measured manually or estimated subjectively (Brewer et al., 2006; Brewer et al., 2007), and allow a faster phenotypic analysis resulting in information with a high degree of consistency and repeatability. Preliminary studies in cotton (Gossypium hirsutum L.) and cucurbits seed testing has shown promising results.

Seeds with $50-75 \%$ filled internal cavity produced normal seedlings, abnormal seedlings and dead seeds (Table 2). This means that different amounts of free space between the tegument and endosperm and/or between the endosperm and embryo, reducing the filled area of seed internal cavity, may negatively affect seed germination in the hybrids studied here. However, the greater the free space between the tegument and endosperm, the less developed the seedlings were produced (Figure 5). At the same time, the intensity of occurrence of abnormal seedlings and non-germinated seeds was directly proportional to the space between the embryo and endosperm (Figure 6). Working with tomato seeds, Van Der Burg et al. (1994) observed that seeds possessing greater free space between the endosperm and embryo rarely managed to produce seedlings with adequate development for transplanting. Additional information about the relation between seed structure can be found in Goodman et al. (2005) Similarly, using bell pepper seeds, Dell'Aquila $(2007 \mathrm{a}, \mathrm{b})$ reported that seeds with free space areas less than $2.7 \%$ on total internal seed area produced a low rate of abnormal seedlings.

Completely full seeds (100\% of internal seed cavity occupied by the embryo and endosperm) classified as abnormal by the X-ray test (Table 1) generated abnormal seedlings and non-germinated seeds in the germination test (Table 2). Radiographed seed A (Figure 7) presented a crack in the cotyledon region, which negatively affected seedling shoot development (Figure 7A). On the other hand, radiographed seed $\mathrm{B}$ presented malformed embryo axis with no differentiation of cotyledonary leaves, endangering the formation of the aerial part of the seedling (Figure 7B).

In general, the X-ray test was effective in detecting damage and abnormalities in Reinger and Sentinel bell pepper hybrids providing additional data comparable to the germination test. This relationship was also verified in tomato (Van Der Burg et al., 1994), corn (Cícero et al., 1998), Mediterranean cypress - Cupressus semprevirens L. (Battisti et al., 2000), white California pepper tree - Lithraea molleoides (Vell.) Engl. (Machado and Cícero, 2003), bell pepper (Dell'Aquila, 2007a) and papaya (Santos et al., 2009) seeds. Furthermore, Goodman et al. (2005) showed that the analyses of X-ray images provided a comprehensive information about the association of seed morphology and seedling performance and should be used as a supplemental procedure to assess the seed physiological potential. In fact, besides the efficacy to identify damages and abnormalities associated with seed germination in bell pepper seeds, the decrease of bell pepper seed internal area occupied by the embryo and endosperm is directed related to the incidence of abnormal seedlings and non-germinated seeds. 

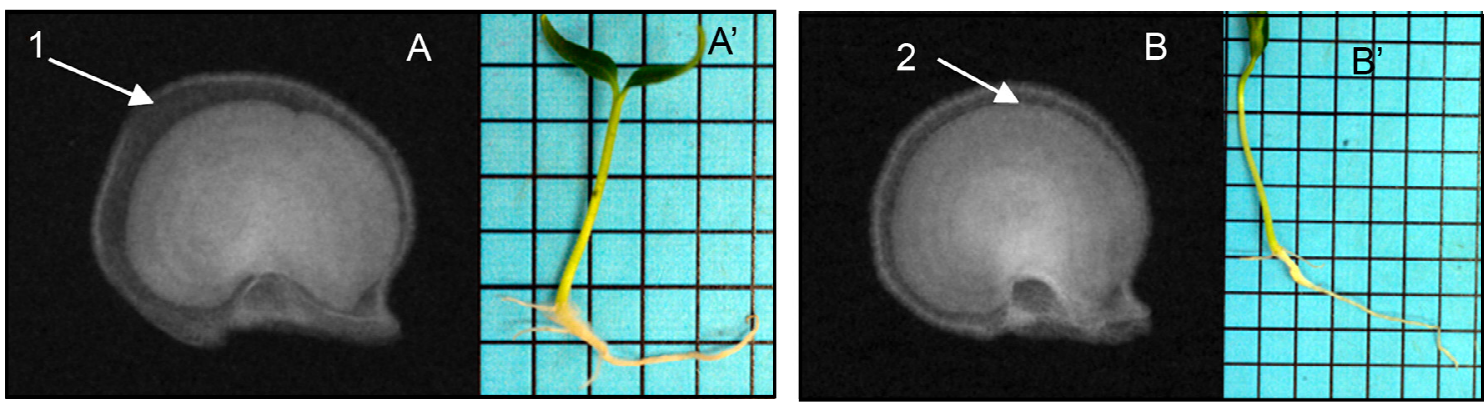

Figure 5 - Radiographic images (A and B) of seeds with 50-75\% occupation (embryo + endosperm) of the internal seed cavity and respective photographic images (A' and $\mathrm{B}^{\prime}$ ) of normal seedlings resulting from the germination test. 1 - greater retraction (dark area between the tegument and endosperm) of the endosperm (A), smaller seedling formed (A'). 2 - smaller retraction (dark area between the tegument and the endosperm) of the endosperm (B), greater seedling formed (B').
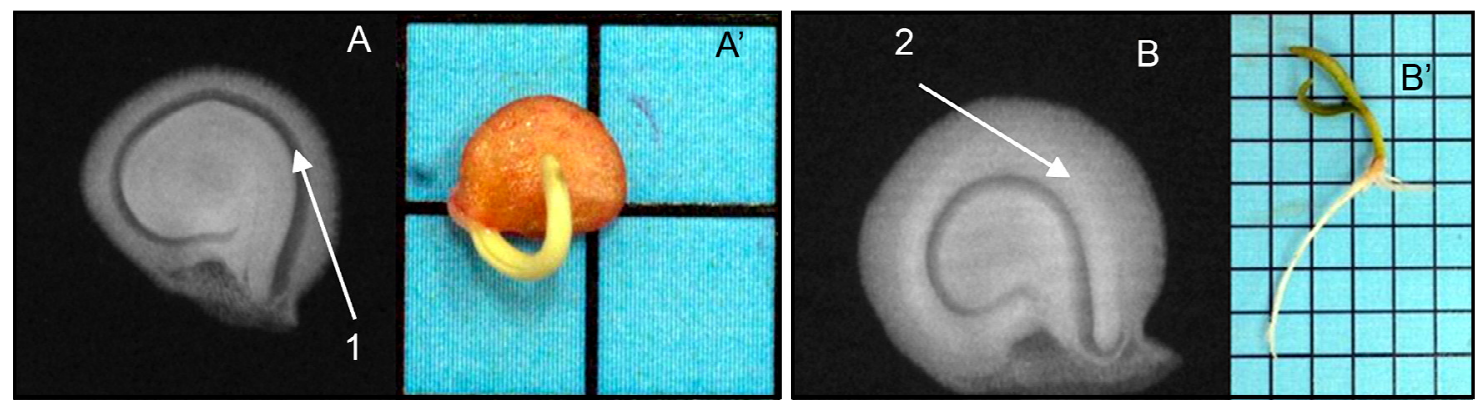

Figure 6 - Radiographic images (A and B) of seeds with 50-75\% occupation (embryo + endosperm) of the internal seed cavity and respective photographic images (A' and $\left.B^{\prime}\right)$ of abnormal seedlings and normal germination test results. 1 - greater space (dark area between endosperm and embryo) (A), greater incidence of abnormal seedlings (A'). 2 - smaller space (dark area between the endosperm and embryo) (B); greater incidence of normal seedlings.
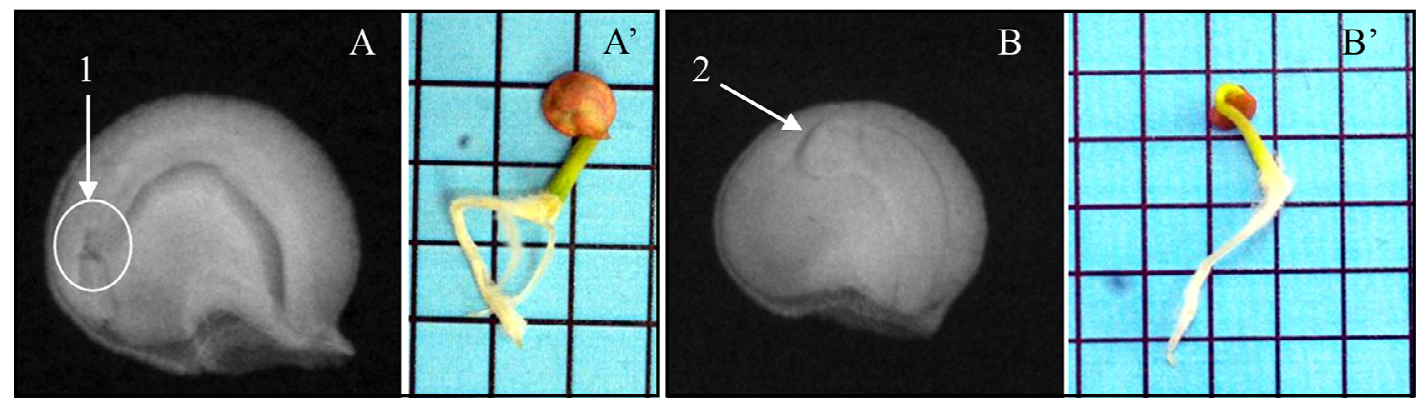

Figure 7 - Radiographic images of abnormal completely full seeds (100\% of internal seed cavity occupied by the embryo and endosperm) (A and B) and respective photographic images of abnormal seedlings ( $A^{\prime}$ and $B$ ') resulting from the germination test. 1 - a crack in the cotyledon tissues. 2 - no differentiation of cotyledon leaves.

\section{Acknowledgements}

To CNPq and FAPESP, respectively, for scholarships and financial support of the project, and to Syngenta Seeds Ltda., for providing seeds for this study.

\section{References}

Battisti, A.; Cantini, R.; Feci, E.; Frigimelica, G.; Guido, M.; Roques, A. 2000. Detection and evaluation of seed damage of cypress, Cupressus semprevirens L. Seed Science and Technology 28: 729738.
Bino, R.J.; Aartse, J.W.; Van Der Burg, W.J. 1993. Non destructive X-ray of Arabidopsis embryo mutants. Seed Science Research. 3: 167170.

Brasil. Ministério da Agricultura, Pecuária e Abastecimento, 2009. Rules for Seed Testing. Brasília, SDA/Mapa/ACS. 399 p. (in Portuguese).

Brewer, M.T; Lang, L.; Fujimura, K.; Dujmovic, N.; Gray, M.; Van Der Knaap, E. 2006. Development of a controlled vocabulary and software application to analyze fruit shape variation in tomato and other plant species. Plant Physiology 141: 15-25.

Brewer, M.T.; Moyseenko, J.B.; Munforte, A.J.; Van Der Knaap, E. 2007 Morphological variation in tomato: a comprehensive study of quantitative trait loci controlling fruit shape and development. Journal of Experimental Botany 58: 1339-1349. 
Carvalho, M.L.M.; Van Aelst, A.C.; Van Eck, J.W.; Hoekstra, F.A. 1999. Pre-harvest stress cracks in maize (Zea mays L.) kernels as characterized by visual, $\mathrm{X}$-ray and low temperature scanning electron microscopical analysis: effect on kernel quality. Seed Science Research 9: 227-236.

Cícero, S.M.; Van Der Heijden, G.W.A.M.; Van Der Burg, W.J.; Bino, R.J. 1998. Evaluation of mechanical damage in seeds of maize (Zea mays L.) by X-ray and digital imaging. Seed Science and Technology 26: 603-612.

Dell'Aquila, A. 2007a. Pepper seed germination assessed by combined $\mathrm{X}$-radiography and computer-aided imaging analysis. Biologia Plantarum 51: 777-781.

Dell'Aquila, A. 2007b. Towards new computer imaging techniques applied to seed quality testing and sorting. Seed Science and Technology 35: 519-538.

International Seed Testing Association [ISTA]. 1996. International rules for seed testing. Seed Science and Technology 24: Supplement.

Machado, C.F.; Cícero, S.M. 2003. Aroeira-branca' [Lithraea molleoides (Vell.) Engl. - Anacardiaceae] seed quality evaluation by the X-ray test. Scientia Agricola 60: 393-397.

Goodman, R.C.; Jacobs, D.F.; Karrfalt, R.P. 2005. Evaluating desiccation sensitivity of Quercus rubra acorns using X-ray. Canadian Journal of Forest Research 35: 2823-2831.

Masetto, T.E.; Davide, A.C.; Silva, E.A.A.; Faria, J.M.R. 2007. Evaluation of Eugenia Pleurantha (Myrtaceae) seed quality by the X-rays test. Revista Brasileira de Sementes 29: 170-174. (in Portuguese with abstract in English).

Pupim, T.L.; Novembre, A.D.L.C.; Carvalho, M.L.M.; Cícero, S.M. 2008. Procedures of the X-ray test to evaluate (Cecropia pachystachya Trec.) seed quality. Revista Brasileira de Sementes 30: 28-32. (in Portuguese with abstract in English)
Rossetto, C.A.V.; Fernandez, E.M.; Marcos-Filho, J. 1995. Procedures to adjust seed moisture content and soybean performance in the accelerated aging vigor test. Revista Brasileira de Sementes 17: 171178. (in Portuguese with abstract in English).

Sahlen, K.; Bergsten, U.; Wiklund, K. 1995. Determination of viable and dead Scots pine seeds of different anatomical maturity after freezing using IDX method. Seed Science and Technology 23: 405-414.

Santos, S.A.; Silva, R.F.; Pereira, M.G.; Machado, J.C.; Borém, F.M.; Gomes, V.M.; Tonetti, O.A.O. 2009. X-ray technique application in evaluating the quality of papaya seeds. Seed Science and Technology 37: 776780.

Simak, M. 1980. X-radiography in research and testing of forest tree seeds. Umea Swedish University of Agriculture Science Nome da revista 3: 1-34.

Simak, M. 1991. Testing of forest tree and shrub seeds by Xradiography. p. 1-28. In: Gordon, A.G.; Gosling, P.; Wang, B.S.P. Tree and shrub seed handbook. ISTA, Zurich, Switzerland.

Simak, M.; Gustafsson, A. 1953. X-ray photography and sensitivity in forest tree species. Hereditas 39: 458-468.

Van Der Burg, W.J.; Aartse, J.W.; Van Zwol, R.A.;Jalink, H.; Bino, F.J. 1994 Predicting tomato seedling morphology by X-ray analysis of seeds. Journal of the American Society for Horticultural Science 119: 258-263.

Received April 19, 2010

Accepted September 15, 2010 